\title{
The value of head circumference measurements after 36 months of age: a clinical report and review of practice patterns
}

\author{
Hector E. James, MD, ${ }^{1}$ Anthony A. Perszyk, MD, ${ }^{2}$ Teresa L. MacGregor, PhD, CPNP, ${ }^{1}$ and \\ Philipp R. Aldana, MD1
}

1Division of Pediatric Neurosurgery, University of Florida College of Medicine Jacksonville, Lucy Gooding Pediatric Neurosurgery Center at Wolfson Children's Hospital, and Baptist Health of Northeast Florida; and 2Division of Clinical Genetics, University of Florida College of Medicine, Jacksonville, Florida

\begin{abstract}
OBJECT The cranium is documented to grow from birth through adolescence. The standard of practice in primary care is measuring head circumference and plotting growth using curves that stop at 36 months. The authors report the importance of their experience with measuring head circumference in the child and same-sex parent beyond 36 months.

METHODS In the University of Florida genetics and pediatric neurosurgery clinics, head circumference is measured and plotted on growth charts through 18 years of age. Circumference and rate of growth over time are compared with those of the same-sex parent. A diagnostic workup is initiated if there is a discrepancy with the patient's head circumference or if there is significant change in the growth rate of the cranium.
\end{abstract}

RESULTS Between January 2004 and December 2007, the lead author examined 190 patients referred by pediatricians and/or pediatric subspecialists because of the concerns regarding head size of the child. Neuroimaging was performed in $70 \%$ of the patients prior to referral. None of the patients had their head size compared with that of their same-sex parent prior to referral. On assessing referring physician responses as to why the same-sex parents, head measurements were not pursued prior to imaging or referral to the specialists, the results were: 1 ) only have head circumference sheets to 36 months of age $(n=28) ; 2)$ the American Academy of Pediatrics does not recommend it $(n=3)$; and 3$)$ the head stops growing at 36 months of age $(n=2)$.

CONCLUSIONS Pediatricians and pediatric subspecialists need instruction on head circumference measurement in children from infancy through adolescence, and when indicated, in comparison with the head size of the same-sex parent. This measurement may be an effective and inexpensive assessment tool.

http://thejns.org/doi/abs/10.3171/2014.12.PEDS14251

KEY WORDS head circumference; child; parent; pediatricians; pediatric subspecialists; congenital

$\mathrm{I}$ N 1968, Nellhaus documented the continuous growth of the cranium of boys and girls through 18 years of age. In reviewing 14 reports in the literature, he found there were no significant racial, national, or geographical differences in head circumference size through 18 years of age. ${ }^{11} \mathrm{He}$ indicated that pediatricians should document head circumference growth through 18 years of age. In 1980, Weaver and Christian documented the importance of comparing head circumference of the child evaluated by the pediatrician to that of the parent. ${ }^{20} \mathrm{He}$ recommend- ed that biological parents accompany the child to the office visit so that the head circumference of the child could be compared with that of the parents.

Emphasis has been placed in health care agencies, health care insurance documents, and other sources of information for primary care providers to measure head circumference up to 36 months of age, ${ }^{1,10,19}$ with limited emphasis for the role of head circumference measurements after 36 months of age despite documentation that the cranium continues to grow until 18 years of age., ${ }^{6,12,16}$ The purpose of this report is

ABBREVIATIONS CDC = Centers for Disease Control and Prevention; UF = University of Florida.

SUBMITTED May 28, 2014. ACCEPTED December 3, 2014.

INCLUDE WHEN CITING Published online May 1, 2015; DOI: 10.3171/2014.12.PEDS14251.

DISCLOSURE This study was supported in part by the Lucy B. Gooding Charitable Foundation Trust and the Baptist Foundation of Northeast Florida, both not-for-profit entities. 
to review the importance of measuring head circumference through 18 years of age. The rationale for this includes, but is not limited to, documenting the head size in proportion to the child's other growth parameters, the rate of growth over time, and the child's head circumference in proportion to that of the same-sex parent, and initiating appropriate diagnostic workup if there is an unexplained microcrania, macrocrania, or significant change in the rate of the growth of the cranium during infancy, childhood, or adolescence. We also addressed whether the referring pediatrician and/ or the pediatric subspecialist measured head circumference of the child after 36 months of age, and whether these treatment providers measured the head circumference of the same-sex parent.

\section{Methods}

\section{Patient Population}

In the period from January 2004 through December 2007, the lead author examined approximately 190 children referred by pediatricians or pediatric subspecialists because of concerns related to the head size of the child. Seventy percent of these patients had undergone some form of neuroimaging prior to referral (cranial ultrasonography, CT, or MRI), ordered by their primary care provider because they believed neurosurgery would not perform a consult without the availability of imaging.

We then wanted to study the issue of head size in children as well as the need for neurosurgical consultation in more detail. A proposal was submitted to the University of Florida (UF) Institutional Review Board to study the issue of the impact of neurosurgery consultations due to a given child's head size on the categories of macrocrania and microcrania. The Board members were informed that more than $90 \%$ of those who underwent imaging prior to referral had no abnormal findings. They requested that the authors focus on a demonstrative group that would highlight the case sampling of macrocrania and microcrania and emphasize unnecessary neuroimaging. The focus was to be part of the review of the charts of the Neurosciences Clinic patients that was then ongoing for the period of 2008-2009. Therefore, a retrospective chart review authorized by the UF Institutional Review Board was performed by the UF Divisions of Pediatric Neurosurgery and Clinical Genetics on patient charts from January 2008 through December 2009. As part of the physical examination protocol, all of the patients evaluated had their head circumference measured and charted on the Nellhaus Scale regardless of age or reason for referral. ${ }^{11}$ For the purpose of review and clinical demonstration, we will present the patients grouped into 3 categories: 1) patients with macrocrania; 2) patients with microcrania; and 3) patients with unrecognized macrocrania.

\section{Patient Groupings}

The first subset of patients was referred by the primary care provider or other referral source to the Pediatric Neurosurgery Center for the concern of having a head that was too large for the patient's age.

The second subset was patients evaluated by the primary care provider or other referral sources referred to the Pediatric Neurosurgery Center and/or UF Division of Clinical Genetics for the primary concern of a small head circumference. These patients were determined by the referring source to have a "head too small for their age."

The last subset was patients referred to the Pediatric Neurosurgery Center who, in childhood or adolescence, had undetected macrocrania at the time of referral from the primary care provider or other referring source. These patients were referred because of concerns including, but not limited to, changes in behavior and/or neurological findings that could be associated with intracranial pathology, or patients who had neuroimaging procedures as part of the primary care workup for neurological findings, with intracranial pathology. All of these patients had a common characteristic of macrocrania that was not recognized by the referring source.

\section{Results}

Results are presented for demonstration of the various referral categories for the purpose of a focused discussion on the subject matter.

\section{Patients With Macrocrania}

There were a total of 11 patients referred to rule out any underlying etiology that was causing progressive intracranial pressure because of the concern "the head was too large for the corresponding age of the patient." Eight patients underwent neuroimaging procedures prior to referral (Table 1). None of the patients had their head measurement compared with that of their same-sex parent prior to imaging and/or referral. When evaluated in the Pediatric Neurosurgery Center, the head circumference of the patient was compared with that of the same-sex parent, if he or she attended the visit.

Nine patients had a head circumference that was proportional in percentile to the same-sex parent on the Nellhaus Scale. ${ }^{11}$ On examination they were all normal. The diagnosis of familial macrocrania was made. No further interventions or imaging procedures were performed. A representative patient of this subset is presented in Fig. 1.

Six of the 9 patients were diagnosed as having "benign subdurals of infancy," as originally described by Robertson et al., ${ }^{14}$ and now more often referred to as "benign extra-axial fluid collections." 7 These patients underwent imaging procedures prior to the referral for macrocrania. No further interventions or surgical recommendations were performed.

Two patients, 2 and 10 months of age, had a head size that was disproportionate to that of the parent of the corresponding sex. On neuroimaging, both these patients had hydrocephalus secondary to aqueductal stenosis. Table 1 summarizes this subset.

\section{Patients With Microcrania}

Five patients with ages ranging from 5 months to 7 years were referred because of the concern of microcrania and the possibility of associated craniosynostosis (Table 2). All patients in this subset underwent imaging studies prior to referral. None of the patients had their head circumference measurement compared with that of their same-sex 
TABLE 1. Macrocrania in infancy*

\begin{tabular}{ccllll}
\hline & & & & \multicolumn{2}{c}{ Head Circumference } \\
\cline { 4 - 6 } Case No. & Age at 1st Visit (mos) & \multicolumn{1}{c}{ Imaging } & \multicolumn{1}{c}{ Physical Examination } & Infant & Same-Sex Parent \\
\hline 1 & 2 & Cranial ultrasound & Normal, full fontanelle & 98 & 95 \\
\hline 2 & 9 & None & Normal, concave fontanelle & 90 & 80 \\
\hline 3 & 12 & Cranial ultrasound & Normal, concave fontanelle & 98 & 98 \\
\hline 4 & 2 & None & Bulging fontanelle, "split" suturesł & 98 & 60 \\
\hline 5 & 8 & None & Normal, concave fontanelle & 98 & 98 \\
\hline 6 & 12 & Cranial ultrasound & Normal, flat fontanelle & 98 & 90 \\
\hline 7 & 6 & Cranial ultrasound & Normal, flat fontanelle & 70 & 65 \\
\hline 8 & 11 & Cranial MRI & Normal, small anterior fontanelle & 98 & 98 \\
\hline 10 & 13 & Cranial MRI & Normal, small anterior fontanelle & 98 & 95 \\
\hline 11 & 10 & Cranial MRI & Bulging fontanelleł & 98 & 45 \\
\hline
\end{tabular}

* None of the patients had their head measurement compared with that of their same-sex parent prior to imaging and/or referral.

$\dagger$ Presented in percentiles from the Nellhaus graph. ${ }^{11}$

$\ddagger$ Subsequently underwent surgery for hydrocephalus.

parent prior to imaging and/or referral. In the Pediatric Neurosurgery Center, the patient head circumference was compared with the same-sex parent, with the exception of 1 patient, whose corresponding parent was not available for assessment. Three patients who had a normal examination and whose head circumference corresponded to similar percentiles of the same-sex parent were diagnosed as having familial microcrania. One female had congenital hypothyroidism and a disproportionately smaller head cir- cumference than her mother. The plain skull radiographs revealed patent cranial sutures. No further interventions or diagnostic procedures were performed. The patient was undergoing follow-up by pediatric endocrinology. The subsequent head circumference measurements indicated the patient's cranium was still growing on the 2 nd percentile of the curve.

One patient was referred at 6 years of age because of microcephaly. Her head circumference was at $46 \mathrm{~cm}$, plac-

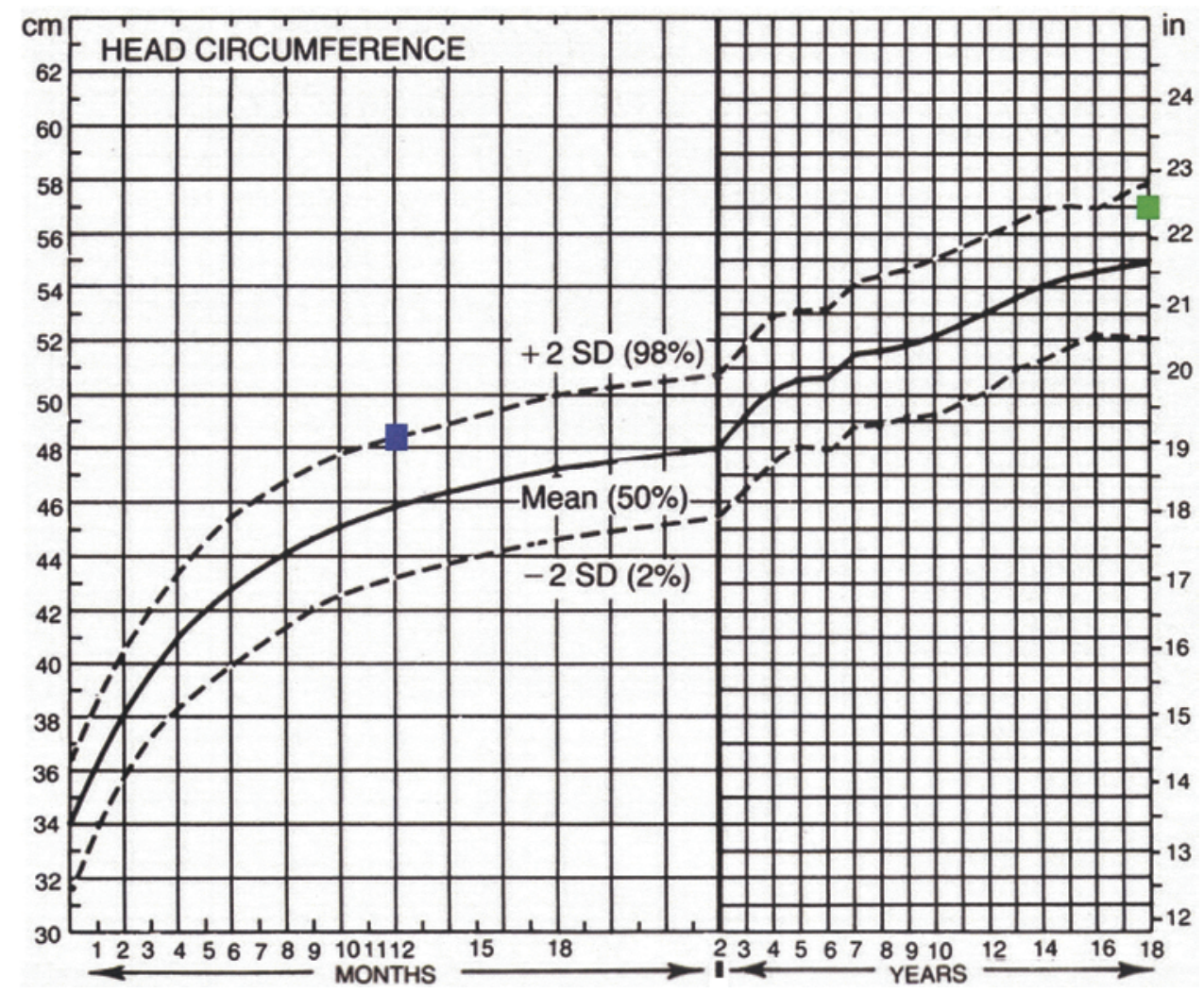

FIG. 1. Head circumference chart of one of the male infants referred due to macrocrania at 12 months of age (blue square). The father's head circumference is plotted on the graph in the 98 th percentile at 18 years of age (green square). 
TABLE 2. Patients with microcrania*

\begin{tabular}{ccclcc}
\hline & & & & \multicolumn{2}{c}{ Head Circumference } \\
\cline { 3 - 6 } Case No. & Age at 1st Visit & \multicolumn{1}{c}{ Imaging } & \multicolumn{1}{c}{ Physical Examination } & Infant & Same-Sex Parent \\
\hline 1 & 8 mos & Head CT scan & Small anterior fontanelle, metopic suture ridge & 2 & NA \\
\hline 2 & 5 mos & Skull radiographs & Small anterior fontanelle & 20 & 15 \\
\hline 3 & 7 mos & Skull radiographs & Small anterior fontanelle & 20 & 10 \\
\hline 4 & 11 mos & Skull radiographs & Small anterior fontanelle, metopic ridge & 20 & 15 \\
\hline 5 & 6 yrs & Cranial MRI & $\begin{array}{l}\text { Small nose, long eyelashes, upslanting palpebral } \\
\text { fissures, small child }\end{array}$ & Under 2 & 60 \\
\hline
\end{tabular}

\footnotetext{
NA = not available.

* None of the patients had their head measurement compared with that of their same-sex parent prior to imaging and/or referral.

$\dagger$ Presented in percentiles from the Nellhaus graph. ${ }^{11}$
}

ing her below the 2 nd percentile. The mother's head circumference was $56 \mathrm{~cm}$ (60th percentile) and the father's head circumference was $60 \mathrm{~cm}$ (well above the 98th percentile) (Fig. 2). The child had a small nose, long eyelashes, upslanting palpebral fissures, wide neck, and short stature. She had a faint voice and was nonverbal. Tapered thin fingers and small feet were also noted. Chromosome and blood-cell analysis showed a small deletion of chromosome 5 (46,XX, del5p15.2). Deoxyribonucleic acid fluorescent in situ hybridization targeted the region of chromosome 5 , which is associated with the syndrome of Cri-du-chat, which finally confirmed the child's underlying condition causing microcephaly, providing a clinical prognosis. Table 2 summarizes this subset.

\section{Patients With Unrecognized Macrocrania}

There were 4 children referred because of symptomatology, but who had macrocrania undetected by the primary care provider. None of the patients had their head circumference measurement compared with that of their same-sex parent prior to imaging and/or referral. At the time of evaluation in the Pediatric Neurosurgery Center, physical examination revealed head circumference well above the 98th percentile on the Nellhaus Scale. ${ }^{11}$ All patients had a history of subtle but progressive deterioration for months to years.

At the time of referral, the 4 patients were $5(n=1), 6(n$ $=2)$, and $14(\mathrm{n}=1)$ years of age. The first patient (5 years old) had a very large retrocerebellar arachnoid cyst. The

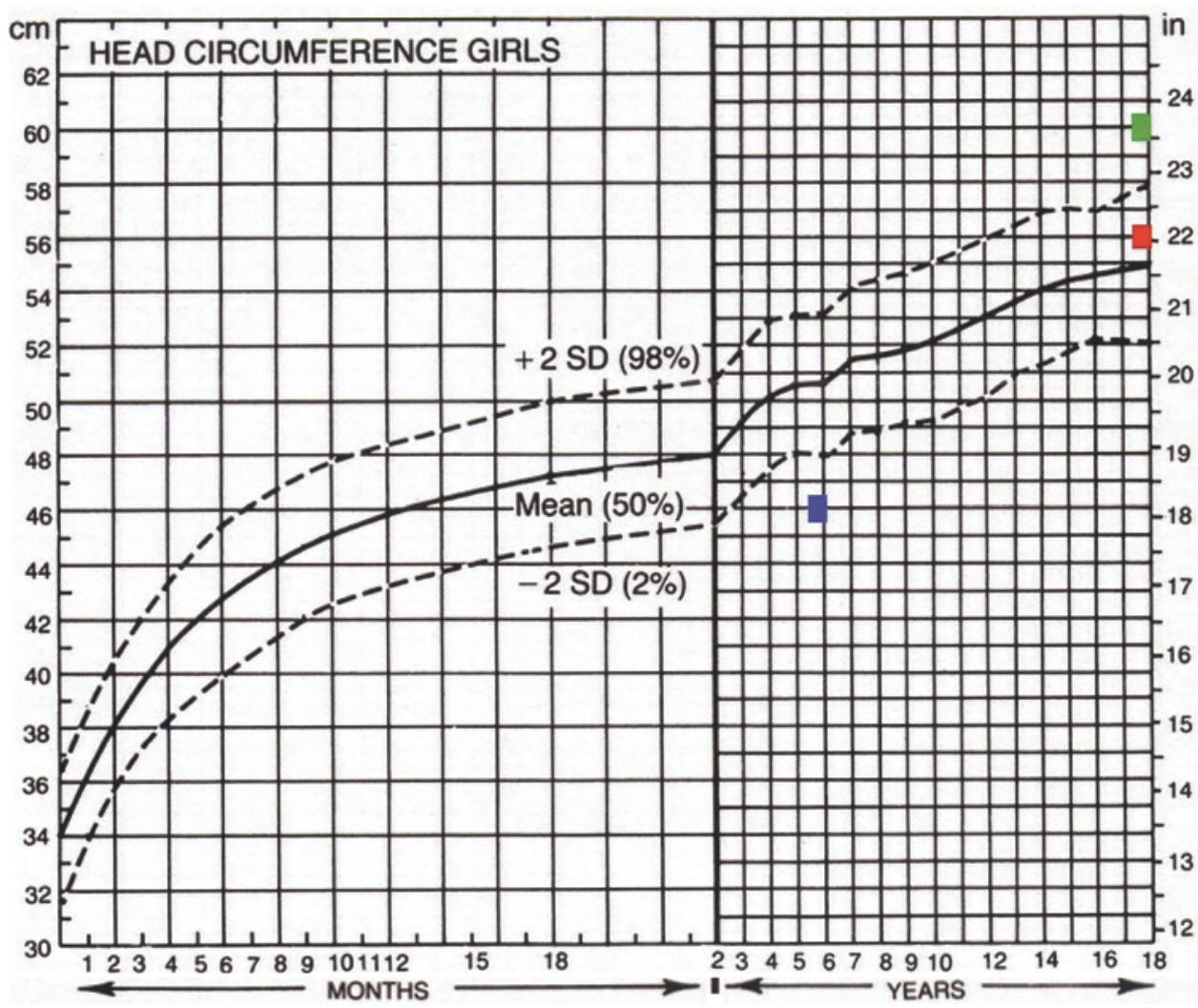

FIG. 2. Head circumference chart of a child (blue square) referred at 6 years of age due to cerebral palsy. The parents' head circumferences were also charted $($ mother $=$ red square, father $=$ green square). 
head circumference at birth was in the 2 nd percentile, and at the time of examination he was above the 98th percentile (Fig. 3).

The second patient had a head circumference well above the 98 th percentile (60 $\mathrm{cm}$ at 6 years old; Fig. 4). He had been referred to clinical genetics for a possible syndromal disorder due to severe motor and developmental delay. On imaging he had severe obstructive hydrocephalus secondary to a midbrain glioma.

The third patient (also 6 years old) was evaluated because of developmental delay and hypotonia. On examination he had macrocephaly (head circumference $57 \mathrm{~cm}$ ), a prominent forehead, broad face, poor muscle tone, joint laxity, and delayed milestones. The father's head circumference was $59.5 \mathrm{~cm}$, which is greater than the 98th percentile, indicating macrocephaly (Fig. 5). The father was noted to have a history of hypotonia and was "a late bloomer." He had a sedentary lifestyle and never participated in sports. Further familial history revealed large heads in both parents' families, which led to a suspicion of a syndromal disorder. A brain CT scan had been performed at 4 months of age because of hypotonia and a large head, and mild ventriculomegaly was present at that time. Magnetic resonance imaging of the brain was performed at 6 years of age and revealed mild ventriculomegaly, but was otherwise normal. Due to the above history, genetics testing was performed for Sotos syndrome. The NSDI gene was positive, which confirmed the diagnosis.

The fourth patient presented at 14 years of age with a 5-month history of headaches, intermittent facial numbness, and ataxia. The patient's head circumference $(59 \mathrm{~cm})$ was well above the 98th percentile (Fig. 6). Magnetic resonance imaging revealed severe hydrocephalus secondary to a pontine and cerebellar astrocytoma.

\section{Head Circumference Measurement After 36 Months of Age by Pediatricians and Pediatric Subspecialists}

In reviewing the referral sources of the patients referred to pediatric neurosurgery because of head size concerns, we identified variations in practice patterns as they relate to measuring the child's head size after 36 months of age, as well as to measuring the head size of the biological parents. Clinical geneticists consistently measured the head size of patients after 36 months whereas pediatricians and other pediatric subspecialists did not. These findings are summarized in Table 3.

When the lead author queried the referring pediatricians and pediatric subspecialists as to why they did not measure the head size after 36 months, and/or consider measuring the head size of the parent when concerns arose about the head size of the child, the most common response was they "did not have head circumference charts that went past 36 months of age." These findings are listed in Table 4.

\section{Discussion}

In 1968, Nellhaus published head circumference tables

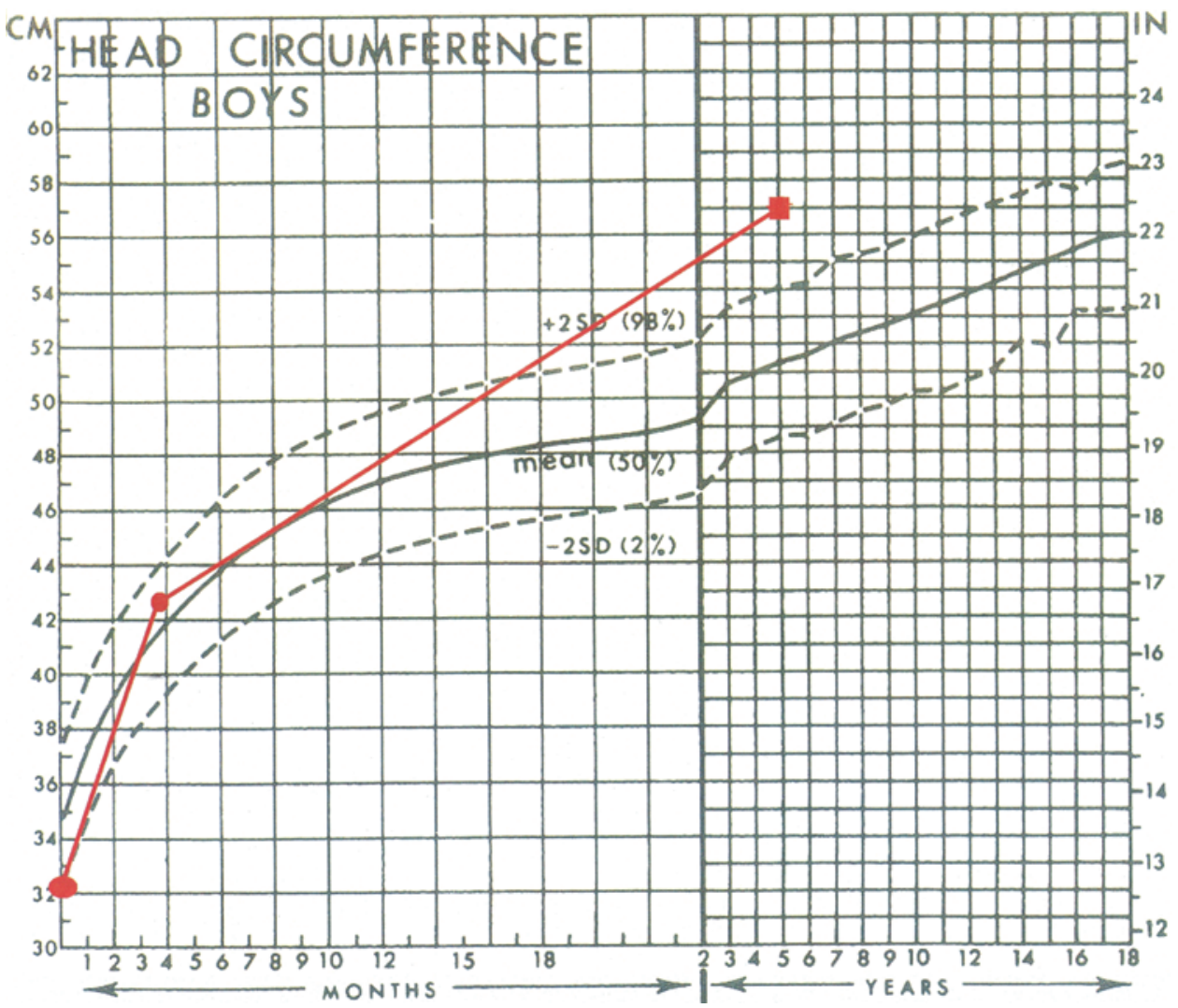

FIG. 3. Head circumference graph of a child referred at 5 years of age because of headaches. The patient's head circumference was plotted back to birth from the pediatrician's notes. 


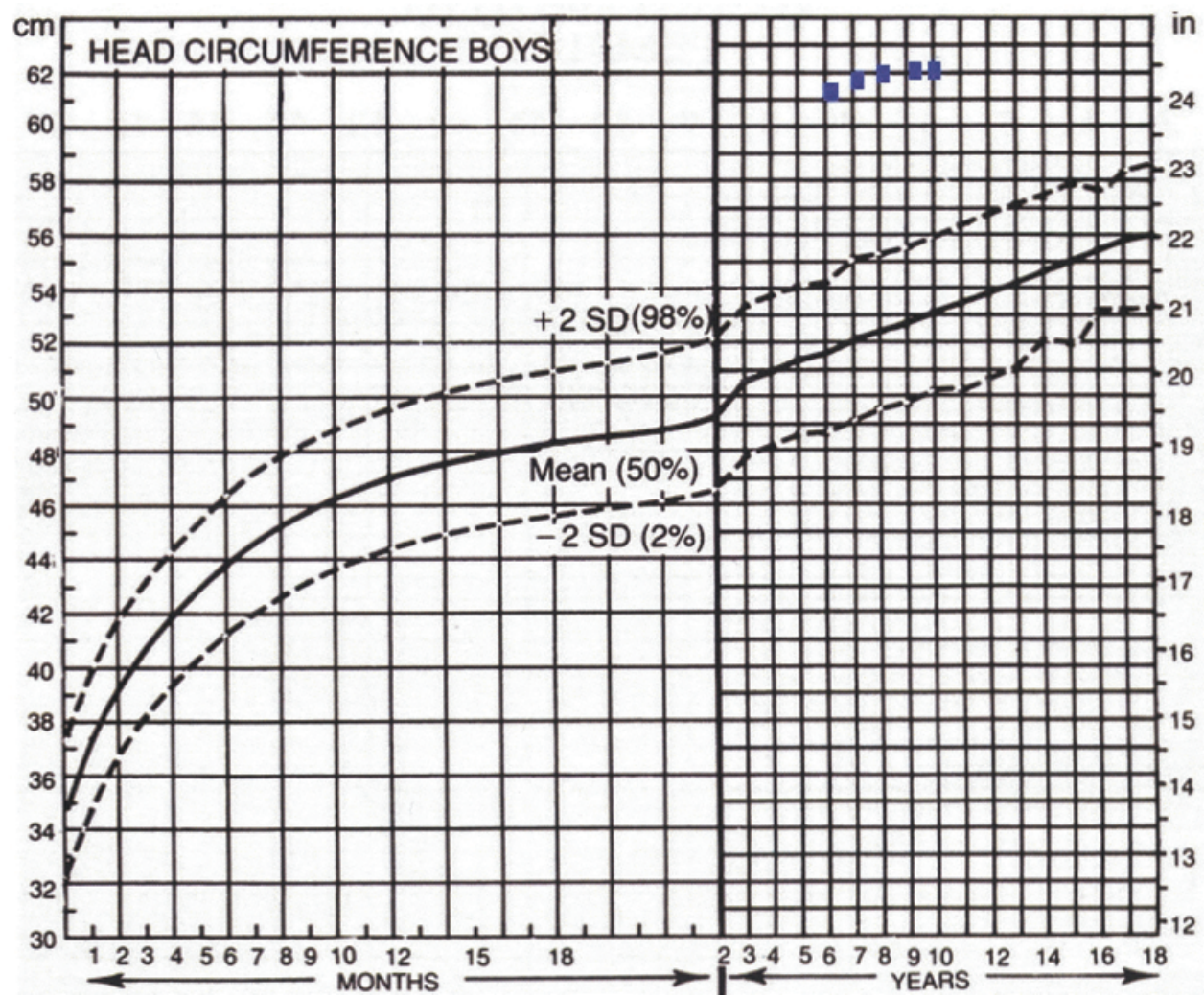

FIG. 4. Head circumference measurements of a 10-year-old child (blue squares) referred at the age of 6 years because of developmental delay and hypotonia. His macrocrania was not recognized.

for boys and girls from birth to 18 years of age, calculated from 14 reports in the literature since $1948 .{ }^{11}$ He concluded there is no significant racial, national, or geographical difference in head circumference. He prepared graphs for males and females from the calculated grand means and standard deviations of each sex at birth and at 1,3, 6, 9, 12, 18 , and 24 months, followed by yearly intervals through age 18 . He found at all ages the mean head circumference of males is $0.9 \mathrm{~cm}$ larger than females, and that head growth under 2 years of age is more rapid for boys than in girls, but then it levels off. The subsequent major growth of the head occurs in girls between 10 and 14 years, and in boys between 12 and 16 years of age.

In 1985 Ounsted and associates reported on a study of serial head circumference measurements (from birth to 7 years of age) of 270 children born in Oxford hospitals between 1970 and $1977 .{ }^{12}$ Results were then compared with those plotted for 1400 children from London published in 1926, and a third series reported for the period 1944 through 1948. ${ }^{17,18}$ The children reported by Ounsted et al. had significantly larger heads at all measured ages from that of the 2 earlier series..$^{12}$ The author noted that this positive secular trend indicates the need for growth charts to be updated with each succeeding generation.

Reports on standards for height and weight from birth to maturity are readily available and not only plot chronological development, but also identify height and weight velocity of growth from birth to maturity. ${ }^{16-18}$ Velocity standards differ from distance standards. In velocity standards, a child does not have the same strong tendency to stay in the same centile position from one age to the other, because there is always a contrary tendency to move from the outer centile position to a more central one in the subsequent year of growth. ${ }^{18}$ The velocity graphs permit the practitioner to identify whether an individual child or adolescent is presently growing "within normal limits."18 After 18 years of age the cranium continues to grow due to increases in the thickness of the skull and scalp, but

TABLE 3. Pediatricians and pediatric subspecialists and measurement of head circumference after 36 months of age

\begin{tabular}{|c|c|c|c|c|}
\hline Head Circumference Measurement & $\begin{array}{c}\text { Primary Care } \\
\text { Pediatrics }(n=25)\end{array}$ & $\begin{array}{l}\text { Clinical Genetics } \\
\qquad(n=3)\end{array}$ & $\begin{array}{l}\text { Pediatric Neurology } \\
\qquad(n=6)\end{array}$ & $\begin{array}{l}\text { Pediatric Endocrinology } \\
\qquad(\mathrm{n}=2)\end{array}$ \\
\hline $\begin{array}{l}\text { Measures head circumference after } \\
36 \text { mos }\end{array}$ & 0 & 3 & 0 & 0 \\
\hline Does not measure after 36 mos & 25 & 0 & 6 & 2 \\
\hline $\begin{array}{l}\text { Measures head circumference of } \\
\text { same-sex parent }\end{array}$ & 0 & 3 & 0 & 0 \\
\hline Does not measure same-sex parent & 25 & 0 & 6 & 2 \\
\hline
\end{tabular}




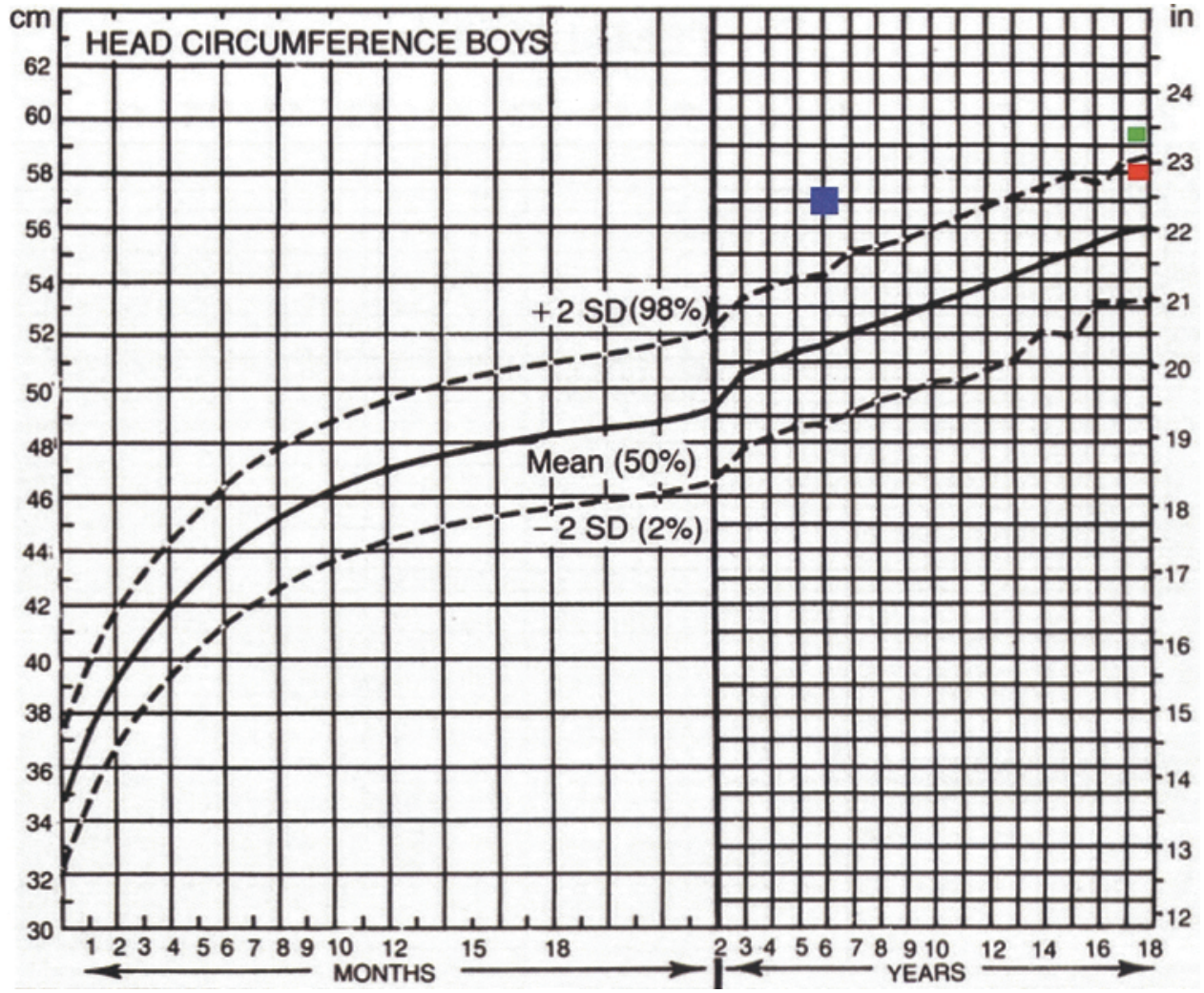

FIG. 5. Head circumference graph of a child (blue square) who was referred with unrecognized macrocrania with progressive and severe motor and developmental delay. Imaging revealed severe hydrocephalus due to a midbrain tumor. The parents' head circumferences were also charted (mother $=$ red square, father $=$ green square).

this accounts for only a $2 \%$ change in the size of the head circumference. ${ }^{6}$

More recently, Rollins et al. studied previous head circumference results and charts, and by drawing on the strengths of these studies they were able to generate a more useful set of male and female head circumference charts for clinical use from birth to 21 years of age. ${ }^{15} \mathrm{We}$ have now converted from the Nellhaus charts to these updated Rollins graphs in our day-to-day practice.11,15 Therefore, when comparing the percentiles of an infant, child, or adolescent to that of the same-sex parent, it is appropriate to assign the parent the measurement at 18 years of age. ${ }^{11}$ The provider must take into account that the child's head circumference may be in a slightly higher percentile than the parent because of larger growth for each subsequent generation. ${ }^{12}$ For individual measurements performed in

TABLE 4. Reasons given by pediatricians and pediatric subspecialists for not measuring head circumference after 36 months

\begin{tabular}{lc}
\hline \multicolumn{1}{c}{ Reason } & $\begin{array}{c}\text { No. of } \\
\text { Patients }\end{array}$ \\
\hline $\begin{array}{l}\text { Do not have head circumference charts }>36 \text { mos of age in } \\
\text { our office }\end{array}$ & 28 \\
\hline $\begin{array}{l}\text { The AAP does not recommend measuring head circumfer- } \\
\text { ence }>36 \text { mos of age }\end{array}$ & 3 \\
\hline The head does not grow after 36 mos of age & 2 \\
\hline
\end{tabular}

AAP $=$ American Academy of Pediatrics. young adults and adults, there are standard head circumference charts. ${ }^{4}$ The authors of these adult charts emphasize that head circumference, as expected, is different for males and females and it is closely related to the height of the individual.

Zahl and Wester reported in 2008 the first populationbased study to investigate the role and importance of the routine use of head circumference measurements in children. ${ }^{23}$ In a retrospective chart review of children under 5 years of age who were diagnosed and hospitalized in Norway due to having an expansive intracranial condition (January 1999 through December 2002), they concluded there was no need for pediatricians to measure the head circumference after 10 months of life. Another review attempted to identify the frequency of symptomatology in children that may assist the primary practitioner in early detection of brain tumors and they did not mention head circumference measurements. ${ }^{3}$

Currently, pediatricians track head circumference in charts that include birth to 36 months of age, which is probably a consequence of the information generated by the National Center for Health Care Statistics of the Centers for Disease Control and Prevention (CDC) in 2000..$^{10}$ The current head growth charts provided by the CDC stop at 36 months of age. ${ }^{1,10}$ In 2007, the American Academy of Pediatrics revised the recommendations for preventive health care and they included head circumference measurements to 24 months of age. ${ }^{2}$ The WHO provides head circumference and growth charts up to 5 years of age, but these are mostly not used by pediatricians in the US. ${ }^{22}$ 


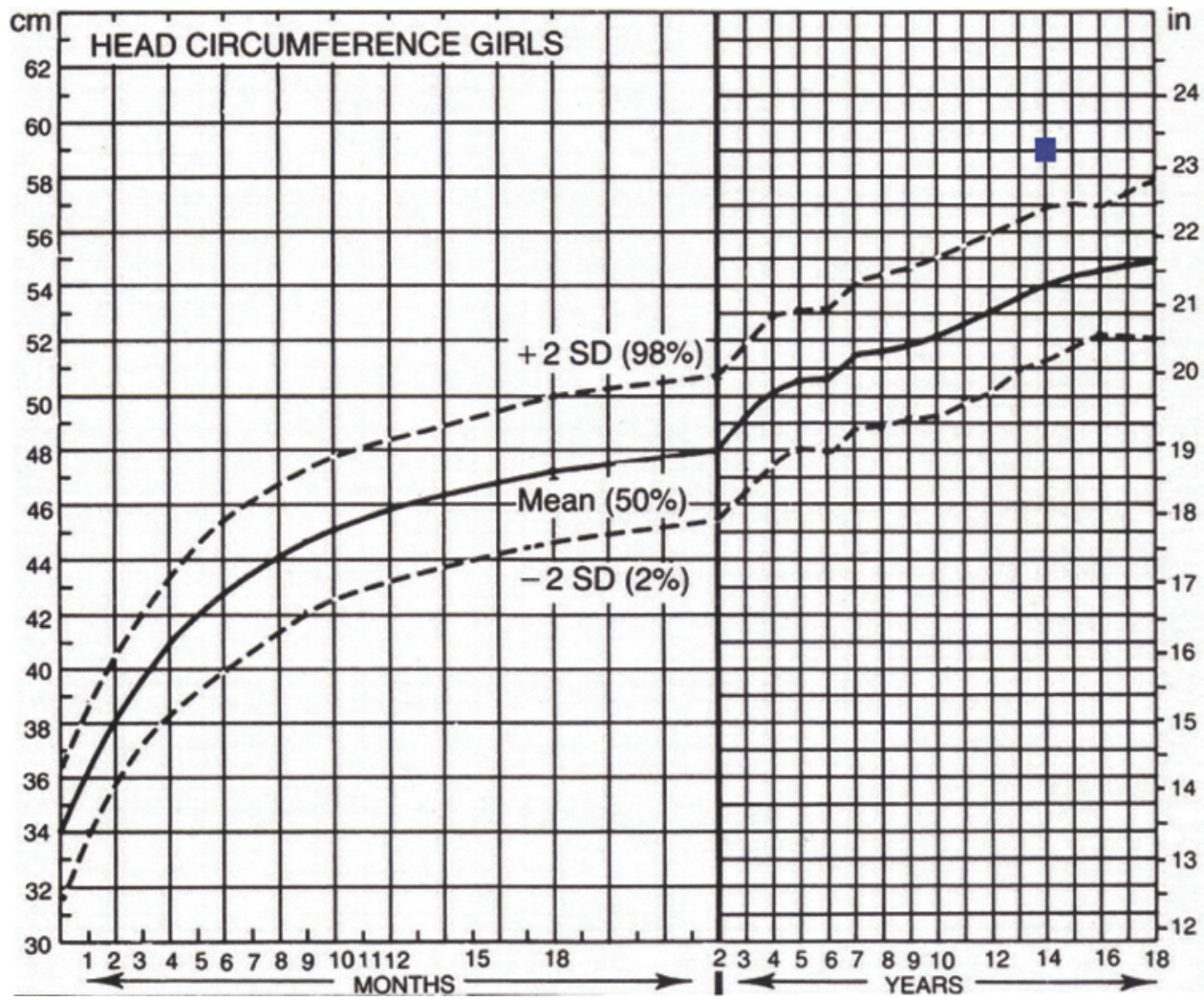

FIG. 6. Head circumference graph of a child referred at 14 years of age with a 5-month history of headaches, ataxia, and facial numbness. The patient had obstructive hydrocephalus due to a tumor.

Documentation, incentives, or practice guidelines for the use of head growth charts from 36 months to 18 years of age have not been required. ${ }^{19}$ These recommendations and reports appear to have generated the prevalent concept in some pediatricians and pediatric subspecialists that the cranium no longer grows after 36 months of age.

In all referrals evaluated by the UF Division of Pediatric Neurosurgery for microcrania and/or macrocrania, we found that no infant, child, or adolescent had their head circumference compared with that of the same-sex parent. When the patient is evaluated in the UF Division of Pediatric Neurosurgery or UF Division of Clinical Genetics, the child's head circumference and previous measurements provided by the referring practitioner are plotted on the head circumference scale. We request the parent of the same sex attend the consultation. ${ }^{20}$ If the biological samesex parent is unable to attend the consultation, an appointment is rescheduled for a subsequent date. The parent's head circumference is also measured and documented on the same scale and the percentiles compared. ${ }^{20}$ If there is a correlation between parental and child measurements, familial microcrania or macrocrania is diagnosed and no studies are requested, with the exception of clinical symptomatology that would mandate further evaluation. It is important to ascertain that the child is normal at the time of examination for the correct diagnosis. Some children may have underlying genetic disorders that should lead to appropriate testing. ${ }^{13}$ If there has been a history of trauma or subdural collections such as hygromas, they may need further assessment?
The vast majority of these cases have an underlying familial or genetic disorder as the cause for the microcrania. ${ }^{8,921}$ The child and his or her family need a thorough evaluation by clinical genetics. The rare case of microcrania due to pansynostosis should also be evaluated by clinical genetics and pediatric endocrinology for hypothyroidism and other disorders. ${ }^{5,21}$

The institution of routine head measurements and plotting using a scale through 18 years of age by pediatric providers, and when appropriate, comparison with the head circumference of the same-sex parent, would potentially reduce unnecessary referrals to specialists as well as reduce medical expenses and use of resources. In addition, the exposure of the child to radiological studies and radiation would be diminished.

\section{Conclusions}

The adoption of head circumference measurement, and when appropriate, comparison with the head circumference of the same-sex parent, will reduce unnecessary referrals and neuroimaging procedures. It may also permit the early detection of intracranial pathology such as insidious hydrocephalus, chronic subdural collections, intracranial tumors, and other chronic pathologies.

\section{Acknowledgment}

We wish to acknowledge the secretarial support by Jennifer Santarone in the preparation of this manuscript. 


\section{References}

1. American Academy of Pediatrics Committee on Practice and Ambulatory Medicine: Recommendations for preventive pediatric healthcare (RE9535). Pediatrics 105:645-646, 2000

2. American Academy of Pediatrics Committee on Practice and Ambulatory Medicine, Bright Futures Steering Committee: Recommendations for preventive healthcare. Pediatrics 120: 1376,2007

3. Ansell P, Johnston T, Simpson J, Crouch S, Roman E, Picton $\mathrm{S}$ : Brain tumor signs and symptoms: analysis of primary health care records from the UKCCS. Pediatrics 125:112119,2010

4. Bushby KM, Cole T, Matthews JN, Goodship JA: Centiles for adult head circumference. Arch Dis Child 67:1286-1287, 1992

5. Davies H, Kirman BH: Microcephaly. Arch Dis Child 37:623-627, 1962

6. Eichorn DH, Bayley N: Growth in head circumference from birth through young adulthood. Child Dev 33:257-271, 1962

7. Hellbusch LC: Benign extracerebral fluid collections in infancy: clinical presentation and long-term follow-up. J Neurosurg 107 (2 Suppl):119-125, 2007

8. Hofman MA: A biometric analysis of brain size in micrencephalics. J Neurol 231:87-93, 1984

9. Mochida GH: Genetics and biology of microcephaly and lissencephaly. Semin Pediatr Neurol 16:120-126, 2009

10. National Center for Health Statistics, Centers for Disease Control and Prevention: Growth Charts. (http://www.cdc. gov/growthcharts/) [Accessed February 25, 2014]

11. Nellhaus G: Head circumference from birth to 18 years. Practical composite international and interracial graphs. Pediatrics 41:106-114, 1968

12. Ounsted M, Moar VA, Scott A: Head circumference charts updated. Arch Dis Child 60:936-939, 1985

13. Paciorkowski AR, Greenstein RM: When is enlargement of the subarachnoid spaces not benign? A genetic perspective. Pediatr Neurol 37:1-7, 2007

14. Robertson WC Jr, Chun RW, Orrison WW, Sackett JF: Benign subdural collections of infancy. J Pediatr 94:382-386, 1979

15. Rollins JD, Collins JS, Holden KR: United States head circumference growth reference charts: birth to 21 years. J Pediatr 156:907-913.e2, 2010

16. Tanner JM: Physical growth and development, in Forfor
JO, Arneil GC (eds): Textbook of Pediatrics. Edinburgh: Churchill Livingston, 1984, pp 278-330

17. Tanner JM, Whitehouse RH, Takaishi M: Standards from birth to maturity for height, weight, height velocity, and weight velocity: British children, 1965. I. Arch Dis Child 41:454-471, 1966

18. Tanner JM, Whitehouse RH, Takaishi M: Standards from birth to maturity for height, weight, height velocity, and weight velocity: British children, 1965. II. Arch Dis Child 41:613-635, 1966

19. Tricare's comprehensive well-child care benefit. Tricare Provider News. Issue 8, 2008, p 3 (https://www.hnfs. $\mathrm{com} /$ content/dam/hnfs/tn/prov/news/pdf/PN\%202008/ PN_8_2008_V4_I8.pdf) [Accessed March 10, 2015]

20. Weaver DD, Christian JC: Familial variation of head size and adjustment for parental head circumference. J Pediatr 96:990-994, 1980

21. Woods CG: Human microcephaly. Curr Opin Neurobiol 14:112-117, 2004

22. World Health Organization: WHO Child Growth Standards: Methods and Development. Head Circumferencefor-Age, Arm Circumference-for-Age, Triceps Skinfoldfor-Age, and Subscapular Skinfold-for-Age. Geneva: World Health Organization, 2007. (http://www.who.int/ childgrowth/standards/second_set/technical_report_2/en/ index.html) [Accessed February 25, 2014]

23. Zahl SM, Wester K: Routine measurement of head circumference as a tool for detecting intracranial expansion in infants: what is the gain? A nationwide survey. Pediatrics 121:e416-e420, 2008

\section{Author Contributions}

Conception and design: James. Acquisition of data: James, MacGregor, Aldana. Analysis and interpretation of data: James, Perszyk, MacGregor. Drafting the article: James. Critically revising the article: James. Reviewed submitted version of manuscript: all authors. Approved the final version of the manuscript on behalf of all authors: James.

\section{Correspondence}

Hector E. James, Pediatric Neurosurgery Center, 836 Prudential Dr., Pavilion Bldg., Ste. 1205, Jacksonville, FL 32207. email: hector.james@jax.ufl.edu. 